\title{
What the differences in conflict between online and face-to-face work groups mean for hybrid groups: A state-of-the-art review
}

\author{
Jessica Kahlow \\ University of Wisconsin-Milwaukee \\ jkahlow@uwm.edu
}

\author{
Hanna Klecka \\ University of Wisconsin-Milwaukee \\ hcklecka@gmail.com
}

\author{
Erin Ruppel \\ University of Wisconsin-Milwaukee \\ ruppele@uwm.edu
}

\begin{abstract}
Conflict has been a topic widely studied in communication and management studies literature. How groups handle conflict can affect group performance, satisfaction, and commitment (Martínez-Moreno, González-Navarro, Zornoza, \& Ripoll, 2009; Pazos, 2012; Staples \& Webster, 2007; Workman, 2007). Much of this literature focuses on online, task-oriented work groups, and how these groups differ from face-to-face (F2F) groups. However, hybrid groups (i.e., those that work both F2F and online) are increasingly common. To better understand conflict in hybrid groups, we review 68 articles regarding online, hybrid, and F2F groups that highlight the differences between F2F and online groups and consider what these differences mean for hybrid groups. In doing so, we identify several emergent themes related to how conflict is managed in online and hybrid groups. The literature suggests that there are many benefits to online and hybrid groups, such as the ability to assemble more diverse teams and work asynchronously, but that conflict is also more common in online than F2F groups. Strong norms and leadership behaviors that encourage trust and cohesion appear to reduce conflict and its effects on group performance and decision making, especially in online groups. These findings suggest that in hybrid groups, F2F meetings might be used to quickly establish group norms, trust, and cohesion, which can then improve online group interactions. However, more research is needed to understand how conflict occurs and is managed in hybrid groups. Future communication research should focus on examining conflict management in hybrid groups using computer-mediated communication perspectives.
\end{abstract}

Suggested citation: Kahlow, J., Klecka, H., Ruppel, E. (2020) What the differences in conflict between online and face-to-face work groups mean for hybrid groups: A state-of-the-art review. Review of Communication Research, 8, 51-77, doi: 10.12840/ ISSN.2255-4165.023

Keywords: Review, Conflict, CMC, Online Groups, Hybrid Groups, Intergroup Communication, Organizational Communication

Editor: Giorgio P. De Marchis (Universidad Complutense de Madrid, Spain).

Open Peer Review Editor: David Schieferdecker (Free University of Berlin, Germany)

Reviewers: Edurne Martinez-Moreno (University of the Basque Country, Spain). A second reviewer prefers to stay anonymous. Open Peer Reviewers: Maura Cherney (Northern Illinois University, USA), Yvonne Montoya (Colorado State UniversityPueblo, USA), Guadalupe Martín-Mora Parra (Universidad de Extremadura, Spain), Sarah Riforgiate (University of Wisconsin-Milwaukee, USA) 


\section{Highlights}

- State of the literature at November 2019.

- Most groups use a combination of face-to-face and online communication, making them hybrid.

- Synthesizes 68 articles on conflict in face-to-face, hybrid, and online task groups and discusses what this means.

- Themes related to conflict in online groups include conflict management styles, decision-making, cultural differences, and trust.

- Group performance as an outcome variable persists across our themes, illustrating the importance of understanding conflict in hybrid groups.

- Future research should examine conflict in hybrid groups using computer-mediated communication perspectives.

\section{Content}

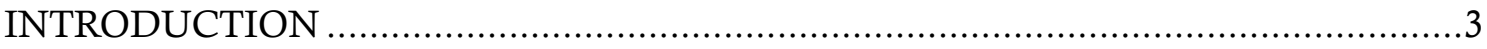

CONCEPTUALIZING ONLINE AND HYBRID GROUPS .......................................

Conceptualizing Online Groups for Future Research. ..................................................4

Why Conflict Differs in Different Group Types ................................................... 5

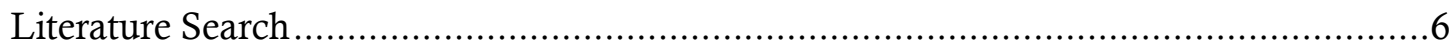

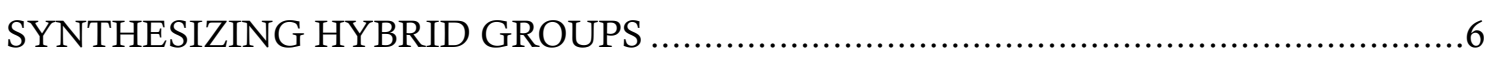

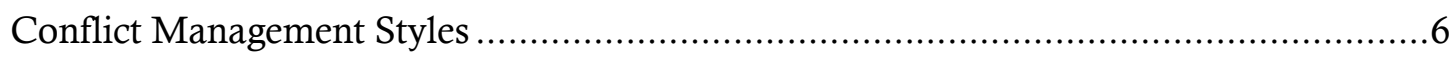

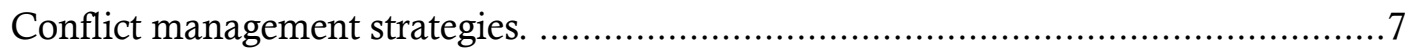

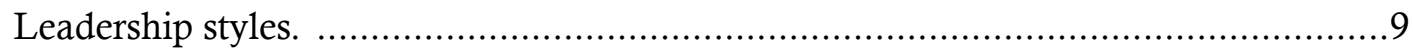

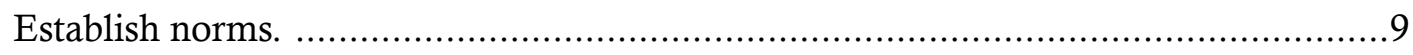

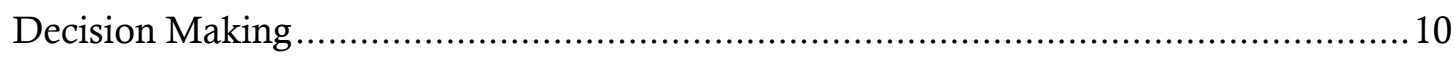

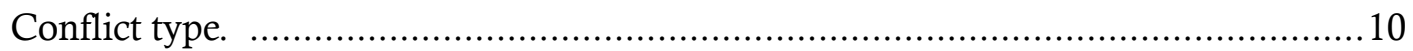

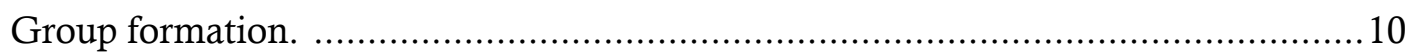

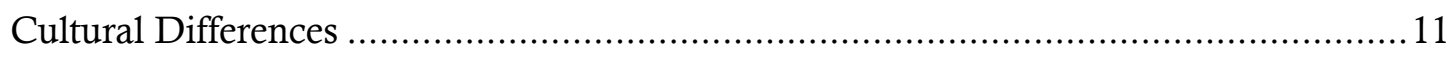

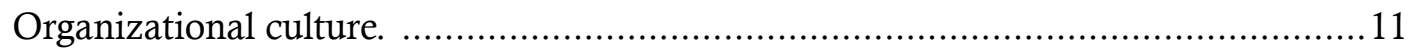

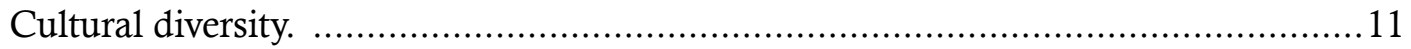

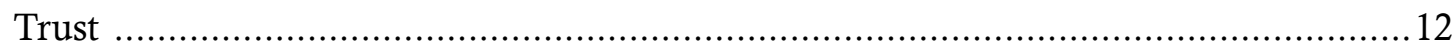

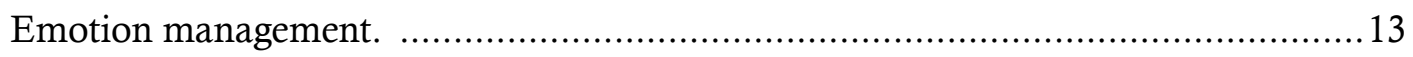

THEMATIC IMPLICATIONS AND FUTURE RESEARCH...................................... 13

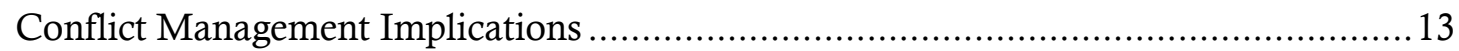

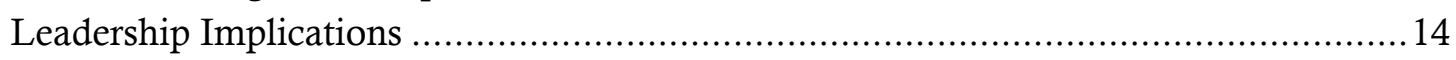

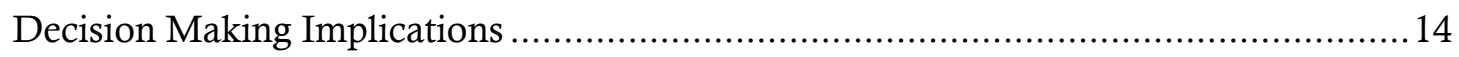

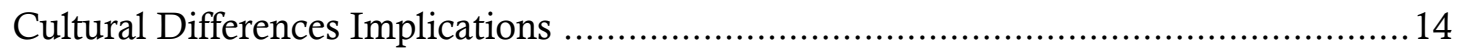

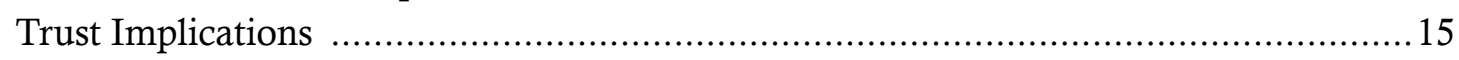

Performance Outcomes .................................................................................... 15

DISCIPLINARY IMPLICATIONS AND FUTURE DIRECTIONS FOR

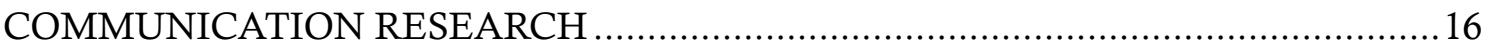

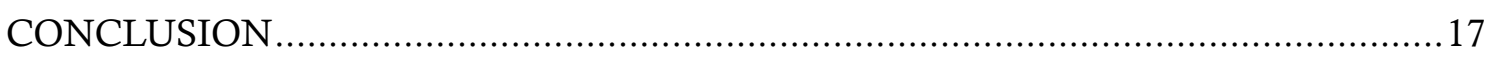

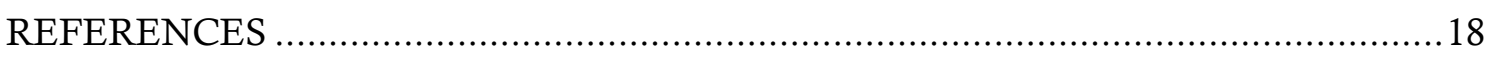

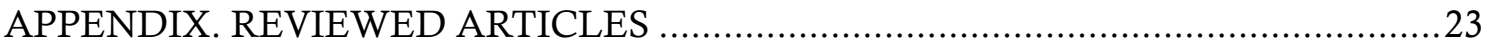

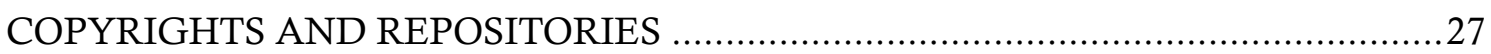




\section{Introduction}

As companies continue to expand geographically and as telecommuting becomes increasingly popular, work groups are increasing their use of computer-mediated communication $(\mathrm{CMC})$ to work together online (Meluch \& Walter, 2012; Mortensen \& Hinds, 2001). Group dynamics surrounding conflict tend to differ between groups that work face-to-face (F2F) and those that work online (Hinds \& Mortensen, 2005; Krawczyk-Brylka, 2017). Although much of the literature on conflict in work groups considers F2F and online groups to be mutually exclusive, work groups often interact through both F2F and online channels. These hybrid groups experience and manage conflict in ways that are distinct from exclusively F2F or online groups (Krawczyk-Brylka, 2017). However, little is known about how conflict is managed in hybrid groups or how our understanding of hybrid groups might be informed by research regarding entirely F2F or online groups. The purpose of this review is to highlight the differences in how conflict is managed in F2F and online groups to help understand how conflict occurs in hybrid groups.

Research on conflict in online groups reflects an intersection of communication scholarship in small groups, mediated, and organizational communication. Hybrid groups using multiple media to communicate are different from exclusively F2F or online groups because the level of virtualness in hybrid groups affects how they manage conflict (Mortensen \& Hinds, 2001). Staples and Webster (2007) note several possible reasons for the differences between traditional, distributed, and hybrid groups. One reason is that hybrid groups may develop in-groups and out-groups if some members are co-located while other members are distributed. In this sense, co-located members might depend more on one another than they depend on their distributed counterparts. Thus, the in-group and outgroup distinction creates an "us versus them mentality" (Staples \& Webster, 2007, p. 68). For example, distributed members might express resentment toward co-located members; co-located group members may place blame on distributed members, and they may establish greater trust, identity, and communication compared to distributed members. In terms of national diversity, safe virtual communication climates mitigate conflict by bridging in-groups and out-groups (Gibson \& Gibbs, 2006).

Group scholarship tends to consider F2F and online mutually exclusive, but doing so leaves out groups that interact both online and F2F. For example, in a work group, group members might begin a discussion in a F2F meeting and continue the discussion later through email or texting. Further, CMC changes the dynamics of conflict because asynchronous online groups lack the interpersonal components that are present in F2F groups, such as nonverbal communication and synchronous feedback (Hinds \& Mortensen, 2005). Much of the existing literature pertaining to conflict in online groups comparatively analyzes groups in F2F versus CMC contexts (Ayoko, Konrad, \& Boyle, 2012; Chiravuri, Nazareth, \& Ramamurthy, 2011; Meluch \& Walter, 2012; Zornoza, Ripoll, \& Peiró, 2002), specifying that research on the latter has been less prevalent due to more recent widespread reliance on CMC for collaboration in organizations (Branson, Clausen, \& Sung, 2008; Lira, Ripoll, Peiró, \& González, 2007).

We begin this review with a definition of online groups. We then conceptualize our literature search. Next, we synthesize the existing literature in terms of the differences between online and F2F groups, and in this process, we identify four major emerging themes prevalent in online and F2F group conflict literature. Then, we address the implications of the differences between how conflict is managed in online versus F2F groups for each theme. Finally, we conclude with a few future directions for communication research.

\section{Conceptualizing Online and Hybrid Groups}

Online, virtual, mediated, CMC, hybrid, distributed, geographically separated, co-located, traditional, F2F, groups, and teams are often used interchangeably and inconsistently. For the purposes of this review, teams are groups that have a specific goal with clear roles and responsibilities (Katzenbach \& Smith, 1993); in other words, all teams are groups, but not all groups are teams. Although many taskoriented work groups would also qualify as teams, we included studies that used the term group or team in our review to capture the full range of research in this area. Given that only some of the research we review deals with teams in the strict sense of the term, we refer to groups throughout the manuscript. Traditional, F2F, and co-located groups all refer to groups that meet in person at the same location. Distributed and geographically separated groups both refer to longdistance groups that use some form of mediated communication to work together. However, co-located 
teams, which are $\mathrm{F} 2 \mathrm{~F}$ virtualness varies within and between groups.

The term virtualness is defined as the amount of CMC used by a group and can be thought of as a continuum spanning from F2F groups to completely online groups (Gilson, Maynard, Young, Vartiainen, \& Hakonen, 2015; Martins, Gilson, \& Maynard, 2004; Stark et al., 2014). Virtualness has also been defined as the distance between team members (Foster, Abbey, Callow, Zu, \& Wilbon, 2015). In addition to a group's degree of virtualness, groups are also defined based on geographical location (Staples \& Webster, 2007). These two components of groups - virtualness and distance - are common to all groups; in other words, all groups have varying degrees of virtualness and varying geographical distances. Because of this variation, we propose that scholars must clearly explicate the groups under analysis according to these two components.

Work groups are able and often expected to communicate via $\mathrm{CMC}$ and F2F, so further research that focuses on hybrid teams is essential for contributing information that addresses the complexities associated with modern group work and CMC theory. The findings more widely available in current research treats F2F and CMC groups as mutually exclusive entities, which might not reflect the group work that actually exists in society. While there are numerous studies pertaining to group conflict that focus entirely on $\mathrm{F} 2 \mathrm{~F}$ or $\mathrm{CMC}$ groups or compare $\mathrm{F} 2 \mathrm{~F}$ with $\mathrm{CMC}$ groups, there are few that consider groups that fall between these categories. Staples and Webster (2007) analyzed traditional (F2F), distributed (CMC), and hybrid groups that harnessed both forms of communication. They determined that to be effective, members of distributed and online groups needed to use open lines of communication, employ effective time management skills, and be more responsive in comparison to $\mathrm{F} 2 \mathrm{~F}$ teams.

Further, Stark et al. (2014) similarly addressed virtualness (or how much CMC is used in a group) of work groups as a continuum and concluded that when teams have the ability to be co-located and online, the type of conflict (task, relational, or process) should determine the level of virtualness the group employs to be effective. For example, Stark et al. (2014) recommended that if there is high-process conflict and the group lacks cooperation, the conflict should be addressed in a F2F setting, rather than virtually. These comparisons between $\mathrm{F} 2 \mathrm{~F}$ and online groups find that conflict management strategies for $\mathrm{F} 2 \mathrm{~F}$ groups do not have the same effectiveness as CMC groups (Stark et al., 2014). Further research on hybrid groups is crucial to extend current understanding in the literature and we would like to encourage future scholars to include various relevant keywords to make sure their work does not get overlooked in future searches, along with clear definitions when using such terms. Finally, since many online and hybrid groups use $\mathrm{CMC}$, future research could also focus on how common theories of CMC (such as social presence theory, media richness theory, social information processing theory, and hyperpersonal perspectives) apply within online and hybrid groups.

\section{Conceptualizing Online Groups for Future Research.}

We present two charts (Figure 1) to represent how past scholarship approaches this area of research, versus what we believe to reflect the modern reality of work groups. In Figure 1, the horizontal axis represents the continuum for the degree of virtualness of the interaction, and where the vertical axis represents the degree of physical distance between interacting members. Virtualness ranges from low (solely face-to-face interactions on the left) to high (people who have only met online on the right). Physical distance ranges from close (groups located within the same office, or groups with little geographical separation, on the bottom) to distant (distributed groups located in multiple locations, often across time zones, on the top). The chart on the left represents a conceptualization of how most of the literature has traditionally approached groups. The chart on the right represents how a small number of researchers have approached groups, which is what we believe to depict reality; most modern work groups should be treated as hybrid groups that dually exist on a spectrum of virtualness and physical distance.

In the literature, F2F and online groups are often considered mutually exclusive entities, even though many groups use multiple media to communicate. A few studies recognized the complexity behind groups using multiple media to communicate. Staples and Webster (2007) differentiated between traditional (F2F), distributed, and hybrid groups, and Stark et al. (2014) recognized the degree of virtualness a group has based on a continuum. However, research does not explicitly address how online or hybrid groups supplement F2F meetings with $\mathrm{CMC}$, how groups use multiple media in different situations, or how to define the type of hybrid group. Hopefully, our proposed depiction that juxta- 


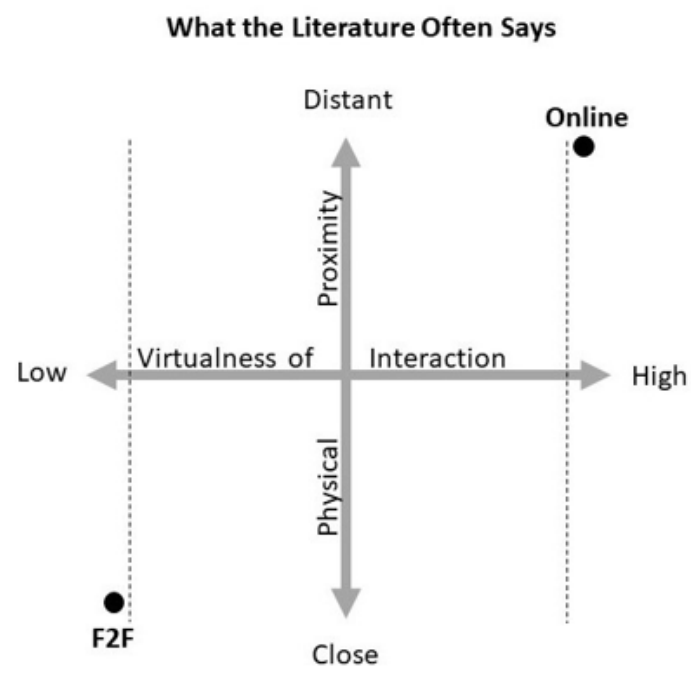

Figure 1. Past Research vs. Reality

poses past research with the reality of modern work groups helps future researchers clarify their definitions of groups and reveals that modern work groups most likely should be considered hybrid groups. Thus, this shared understanding can lead to future research that addresses how groups use mixed media in their group communication.

\section{Why Conflict Differs in Different Group Types}

Whether significant differences exist among the type of group (F2F, virtual, or hybrid with varying degrees of closeness) is contested both theoretically and empirically. Theoretically, Short and Christie (1976) argue that the reduced social presence in many media used to collaborate leads to differences in group interactions and outcomes; media with less presence would have worse interactions than media with more presence. However, more recent notions of social presence theory and other media capacity theories argue that these differences are not significant. For instance, Walther and Burgoon (1992) found that CMC group members expressed positive feelings about one another in a way that mirrored F2F groups. Likewise, Hollingshead and Contractor (2002) find no significant differences in interpersonal behaviors in terms of communication and group performance between F2F and CMC groups, especially in longitudinal observations. Further, Montoya, Massey, Hung, and Crisp (2009) suggest that the general pervasiveness of media among members of co-located and distributed groups is so

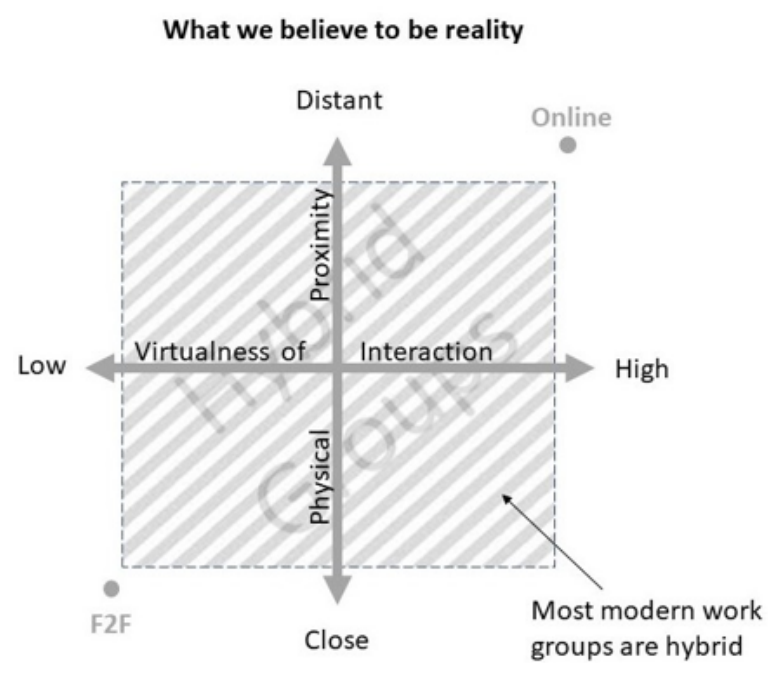

high that members' interactions and behaviors with one another via CMC are not necessarily different.

The geographical distance between group members also influences group members' experiences. In a mixed-method comparison of F2F, hybrid, and distributed groups, Staples and Webster (2007) found that the relationships between teamwork, ability to cope, and performance were higher in hybrid and distributed groups than in F2F groups. They explain this difference as being an outcome of geographical distance more so than CMC in the sense that distributed group members have fewer opportunities to gather informal feedback compared to their co-located counterparts (Staples $\&$ Webster, 2007). Thus, they argue that it is more important for virtual and hybrid group members to know who to go to in the organization to get a prompt response than it is for F2F group members, since they have more opportunities to interact with members of the organization.

Virtuality also influences group members' experiences in online, hybrid, and F2F groups. Workman (2007) examined how virtualness impacts group performance and found that hybrid groups perceived less conflict and had better performance than F2F and virtual groups. Ocker and Morand (2002) used an experiment to examine hybrid and online groups and found that hybrid group members perceived more cohesiveness, a greater ability to manage conflict, and greater satisfaction compared to purely CMC groups. Similarly, Martínez-Moreno, González-Navarro, Zornoza, and Ripoll (2009) used an experiment to examine how conflict 
in videoconference, $\mathrm{CMC}$, and $\mathrm{F} 2 \mathrm{~F}$ groups influences group performance; they found that videoconference groups performed the best while CMC groups performed the worst.

Specifically, F2F group performance was enhanced by both task (i.e., the group's primary goal) and process (i.e., the logistics around how the group accomplishes that goal) conflict, but task conflict decreased performance in videoconference groups (Martínez-Moreno et al., 2009). Further, process and relationship (i.e., interpersonal) conflict was particularly detrimental to CMC groups, relative to F2F groups, at later stages of group development. MartinezMoreno et al.'s findings regarding F2F groups are generally consistent with those of a later meta-analysis (de Wit, Greer, \& Jehn, 2012), but their findings regarding videoconferencing and CMC groups suggest that associations between various conflict types and group performance likely differ in online and hybrid groups, perhaps because as virtuality increases, the opportunity for casual interactions with group members decreases, specifically in dispersed groups.

\section{Literature Search}

The literature search was conducted in November 2019 and included the following databases: Academic Search Complete, ComAbstracts, Communication \& Mass Media Complete, JSTOR, ProQuest, Web of Science, and Social Science Open Access Repository. We also used Google Scholar to find additional articles and for citation chasing. These databases were chosen because they are well-known within the field of communication, and together, the articles within these databases provide a strong foundation for us to conduct our search. The following terms were used to search article titles, subjects, keywords, and abstracts: ("conflict" OR "conflict management" OR "conflict resolution" OR "conflict strategies" OR "conflict handling") AND ("online group" OR "online team" OR "hybrid group" OR "hybrid team" OR "distributed group" OR "distributed team" OR "mediated group" OR "mediated team" OR "virtual group" OR "virtual team"). An initial search revealed 132 articles related to conflict in online groups. Each author repeated the search, and these secondary searches did not yield any new articles. As such, we determined that an exhaustive search was conducted. To be included in the review, an article needed to be recoverable, written in English, and peer-reviewed. Both quantitative and qualitative studies were included. A complete list of the articles used in the review is available in the Appendix.

After sorting the articles to exclude articles that did not look at both online and F2F groups or hybrid groups as they relate to the central topic of conflict, a total of 68 articles from 49 different journals and books were included in this review. The primary reason a study was excluded was because it focused only on F2F groups, as opposed to online groups or comparisons between the two. The search revealed three literature reviews that offered general assessment of literature on online or virtual groups and only briefly discussed the presence of conflict among them (Gibbs, Kim, \& Boyraz, 2017a; Gibbs, Sivunen, \& Boyraz, 2017b; Gilson et a1., 2015). However, many sources included in Gilson et al. (2015) are now more than a decade old and seem to be limited to management-related sources. Further, Gibbs et al. (2017a) and Gibbs et al. (2017b) focus on virtual teams in general and only briefly discuss the topic of conflict within subsections of each review. To determine the themes for this study, we used Machi and McEvoy's (2016) recommendations for creating literature reviews. In the next section, we synthesize the literature surrounding online groups by theme: conflict management styles, decision making, cultural differences, and trust.

\section{Synthesizing Hybrid Groups}

Research on conflict in F2F group settings currently dominates the literature. Nevertheless, recent research on CMC demonstrates that productive task-oriented work is being completed using online groups. The themes regarding taskoriented conflict in online groups that have emerged in the research include (a) conflict management styles, (b) decisionmaking, (c) cultural differences, and (d) trust and emotion management. Next, we offer an in-depth review of each theme to provide a clearer understanding of what is known about group conflict in online contexts, as well as determining areas in need of additional research and exploration within each theme. Finally, we conclude with general areas for future research and our overall conclusions based on the literature. A summary table of findings of what is known and areas for future research about each theme is available in Table 1.

\section{Conflict Management Styles}

A dominant theme in existing research is the identification 
that conflict among online groups can be complex. Scholars consistently argue that conflict theory, which has been traditionally applied to teams in F2F settings, is not necessarily applicable to teams using $\mathrm{CMC}$, often due to factors associated with online groups such as reduced social presence, lean media, and varied communication norms (Montoya-Weiss, Massey, \& Song, 2001). Consequently, researchers offer insights into how members can resolve and mitigate conflict (Hinds \& Bailey, 2003; Shin, 2005). Thomas's (1992) identifies five conflict management styles with varying degrees of cooperativeness and assertiveness: competing (uncooperative/assertive), avoiding (uncooperative/ unassertive), collaborating (cooperative/assertive), accommodating (cooperative/unassertive), and compromising (somewhat cooperative/somewhat assertive). For the purposes of this review, we consider uncooperative strategies (competing and avoiding) negative conflict management strategies and cooperative strategies (collaborating and accommodating) positive conflict management strategies.

\section{Conflict management strategies.}

Other scholars align their online group research with traditional conflict management styles (see Thomas, 1992). Zornoza et al. (2002) discovered that the likelihood that a team employs negative conflict management strategies (avoiding, obliging, dominating) is significantly higher in online groups. Yu and Kuo (2012) performed a content analysis of virtual group discussions in an online class setting. They found that conflict is an inevitable group process and provides other group members the opportunity to adjust their values and preferences accordingly. They found that when virtual groups used withdrawal strategies, they would miss out on opportunities to talk about problems in the group (Yu \& Kuo, 2012).

Additionally, Lee, Panteli, Bülow, and Hsu (2018) conducted a field study where they used adaptation theory, and they found that international groups used email to prevent conflict. They identified interaction avoidance, disempowering, blame-protection, and image-sheltering as the primary conflict strategies used to maintain organizational relationships in conflict situations occurring via email. Relatedly, Paul, Samarah, Seetharaman, and Mykytyn (2004) found that the collaboration conflict management style was associated with positive group performance among virtual groups.

Correia (2008) investigated the conflict management strategies used in an information and communication tech- nology (ICT) rich graduate student classroom and found that all three groups experienced conflict, and that conflict changes over time. Specifically, ICTs promoted conflict management by simply offering group members a way to communicate (Correia, 2008). Olaniran (2010) examined conflict management patterns in email communication using an experimental design and found that the type of task influences the group's conflict management styles. Specifically, it is best to confront group members if there is intellective or cognitive task conflict. Thus, it is important to negotiate conflict strategies based on the kind of task and technology used (Olaniran, 2010). Martínez-Moreno, Zornoza, Orengo, and Thompson (2015) longitudinally examined the differences in conflict management styles in trained and untrained synchronous CMC groups using an experimental design and content analysis. They found that selfguided conflict management training is useful for virtual groups because trained groups used positive conflict management strategies (e.g., open communication and rotating responsibilities) more often than negative conflict management strategies (e.g., avoiding) over time. Untrained groups tended to use negative conflict strategies more often over time (Martínez-Moreno et al., 2015).

Online groups also lack many nonverbal cues necessary to interpret meaning and intent. Hinds and Bailey (2003) found that using a collaborative approach to managing conflict improves performance; however, collaborative norms can be difficult to establish among online teams due to the lack of certain antecedents, including mutual attraction, trust, cohesion, and interaction opportunities, which are negatively influenced by distance and technology. Furthermore, the lack of trust is a consistent factor that impacts conflict management styles of online groups (Furumo, 2009). Trust among members is necessary for cooperation to take place (Baruch \& Lin, 2012), and others have found a strong association between trust, collaborative conflict management, and teamwork satisfaction among online groups (Xiaojing Liu et al., 2008).

Further, online groups that lack trust could end up employing competitive or avoidance styles of conflict management, which can have negative effects on group performance. Some scholars focus on coopetition (the intersection of cooperation and competition) as it relates to job effectiveness, citing that because competition often inhibits the pooling of information, competitive conflict should be closely monitored, and cooperative tendencies should be encouraged 
Table 1. Summary of findings

\begin{tabular}{|c|c|c|}
\hline Theme & What we know & Areas for further research \\
\hline $\begin{array}{l}\text { Conflict Management } \\
\text { Styles }\end{array}$ & $\begin{array}{l}\text { - Conflict in online groups requires strategic approach- } \\
\text { es to conflict management (Hinds \& Bailey, 2003; Shin, } \\
\text { 2005). } \\
\text { - Collaborative approaches improve group performance } \\
\text { (Hinds \& Bailey, 2003). } \\
\text { - It is important to determine group norms early on } \\
\text { (Ayoko et al., 2012; Pazos, 2012; Xiaojing Liu et al., } \\
\text { 2008), and a lack of group norms lead to avoiding, } \\
\text { competing, and compromising approaches (Thomas, } \\
\text { 1992; Zornoza et al., 2002). } \\
\text { - Leader behaviors moderate the relationship between } \\
\text { reactions to conflict and group outcomes (Ayoko \& } \\
\text { Callan, 2010; Chen \& Chang, 2005; Garrison et al., 2010) }\end{array}$ & $\begin{array}{l}\text { - How can conflict facilitate constructive } \\
\text { engagement among group members? } \\
\text { - How effective are conflict management } \\
\text { strategies across media (email, instant-mes- } \\
\text { saging, etc.) } \\
\text { - What is the relationship between con- } \\
\text { flict or conflict management and leadership } \\
\text { styles? } \\
\text { - How does conflict manifest in hybrid } \\
\text { groups, which use both CMC and F2F to } \\
\text { exchange information? } \\
\text { - How do leaders of online groups manage } \\
\text { conflict? }\end{array}$ \\
\hline Decision Making & $\begin{array}{l}\text { - F2F groups make better decisions than online groups, } \\
\text { especially when a correct solution exists (O’Neill et al., } \\
\text { 2016). } \\
\text { - } \quad \text { Anonymity in group decision making does not } \\
\text { guarantee better decisions (Postmes \& Lea, 2000). } \\
\text { - Performance in online groups depends on social } \\
\text { context and social norms (Postmes \& Lea, 2000). } \\
\text { - F2F groups make decisions about three times as fast } \\
\text { as online (instant message) groups (O'Neill et al., 2016). } \\
\text { - } \quad \text { Type of conflict helps determine degree of virtualness } \\
\text { that should be applied (Branson et al., 2008; Gilson et al., } \\
\text { 2015; O'Neill et al., 2016; Postmes \& Lea, 2000) }\end{array}$ & $\begin{array}{l}\text { - Is the relationship between conflict and } \\
\text { decision-making positive or negative? } \\
\text { - Replicate prior studies that had mixed } \\
\text { findings. } \\
\text { - Possible area for a future meta-analysis. }\end{array}$ \\
\hline Cultural Differences & $\begin{array}{l}\text { - Positive outcomes associated with diverse online } \\
\text { groups are often not realized due to conflict (Sessa, 1996; } \\
\text { Shin, 2005). } \\
\text { - Negative outcomes of cultural differences inhibit } \\
\text { group members' perceptions of performance (Ferreira et } \\
\text { al., 2012; Montoya-Weiss et al., 2001; Yilmaz \& Peña, } \\
\text { 2014). } \\
\text { - Increased risk for miscommunication in diverse } \\
\text { online groups (Ayoko et al., 2012; Horwitz et al., 2006; } \\
\text { Montoya-Weiss et al., 2001). } \\
\text { - Lack of a single organizational culture and physical } \\
\text { environment contribute to conflict in diverse CMC } \\
\text { groups due to miscommunication (Hinds \& Mortensen, } \\
\text { 2005; Horwitz et al., 2006; Montoya-Weiss et al., 2001). } \\
\text { - Conflict management strategies created for F2F } \\
\text { groups do not have the same effectiveness in CMC groups } \\
\text { (Martínez-Moreno et al., 2012) }\end{array}$ & $\begin{array}{l}\text { - How do we best manage conflict cross- } \\
\text { culturally? } \\
\text { - Do specific cultural groups have differ- } \\
\text { ent signs of conflict in online groups? } \\
\text { - How do diverse groups develop and } \\
\text { maintain trust, and how does this vary } \\
\text { across cultures? } \\
\text { - What are strategies for alleviating } \\
\text { miscommunication (rich vs. lean media)? } \\
\text { - Replicate prior studies that had mixed } \\
\text { findings }\end{array}$ \\
\hline
\end{tabular}




\begin{tabular}{|c|c|c|}
\hline $\begin{array}{l}\text { Trust and } \\
\text { Emotion Management }\end{array}$ & $\begin{array}{l}\text { - Trust is crucial to group performance in online groups } \\
\text { and relationship building helps build trust in online groups } \\
\text { (Garrison et al., 2010). } \\
\text { - Trust mediates the influence communication has on } \\
\text { performance in hybrid groups (Sarker et al., 2011). } \\
\text { - Relationship between online group members becomes } \\
\text { stronger as knowledge-based trust increases (Jarvenpaa et } \\
\text { al., 2004; Kuo \& Yu, 2009). } \\
\text { - Groups function better when emotions are communi- } \\
\text { cated (Ayoko et al., 2012). }\end{array}$ & $\begin{array}{l}\text { - What is the relationship between trust and } \\
\text { conflict management? } \\
\text { - How to create high levels of trust initially } \\
\text { and maintain it throughout the duration of the } \\
\text { group's task? } \\
\text { - What is the influence of emotion manage- } \\
\text { ment on conflict management in online } \\
\text { groups? } \\
\text { - How and when should emotions be shared } \\
\text { in groups? }\end{array}$ \\
\hline
\end{tabular}

(back to pg. 56, forward to pg. 63)

among members (Lin, Wang, Tsai, \& Hsu, 2010).

At the same time, ICTs also provoked conflict when specific strategies for using ICTs were imposed, when group members had different perceptions of urgency for responding to group messages, and when group members were blunt with others in the group (Correia, 2008). Meyer, Bond-Barnard, Steyn, and Jordan (2016) use a cross-sectional survey to gauge practitioners' preferences for video conferencing and F2F meetings. They found that practitioners preferred $\mathrm{F} 2 \mathrm{~F}$ over $\mathrm{CMC}$ and that they perceived CMC groups to be less cohesive, have less trust, and have more communication breakdowns, but that they did not perceive CMC groups as having more conflict (Meyer et al., 2016).

\section{Leadership styles.}

Several studies focus on the influence of leadership styles on a team's task and social outcomes. Different leadership styles can have different effects on the degree and nature of conflict in work teams (Ayoko \& Callan, 2010). Further, Ayoko and Callan (2010) argue that group leaders serve as a bridge that connects group members in meaningful ways, helping them reach team goals. They also found that leader behaviors that have stronger emotional management qualities were strongly associated with better task conflict management and group outcomes. While their study included 97 workgroups, it is unclear the extent to which the groups used CMC in their interactions. Given the groups were located in a geographically similar location, they could have met F2F or via CMC. Based on the literature, the connection between leadership and conflict management styles in online groups is unclear.
Chang and Lee (2013) examine how leadership style influences the type of conflict management among Taiwanese business students working on a group project. These are hybrid groups because students met in class and worked on their projects via an online platform. They found that collaborative approaches to conflict are most effective, and that transformational leadership is more effective for dealing with conflict. Similarly, Gilson et al. (2015) found that virtuality strengthens the relationship between inspirational leadership, commitment, and trust, but dampens the relationship between hierarchical leadership and performance.

\section{Establish norms.}

In online groups, it is important to establish norms early in the development of an online group. Communication norms among online groups can include the types of information shared over various media, codes of conduct for behaviors (such as responding to or initiating messages), and expectations associated with prioritizing message importance for collocated versus remote team members (Cramton \& Orvis, 2003). Hinds and Bailey (2003) contend that if "conflicthandling norms" (p. 628) that improve group performance and future conflict interaction are not established early or maintained throughout the group's lifetime, less desirable styles of conflict management (i.e., competing, compromising, or avoiding) are more likely to manifest among members. Many scholars agree that this responsibility of early conflict management falls on the team's leader (Chen \& Chang, 2005), and failure by the leader to do so early in team formation leads to poorer performance, regardless of individual members' skill sets (Garrison, Wakefield, Xu, \& Kim, 
2010; Wakefield, Leidner, \& Garrison, 2008).

The idea that establishing early process norms and preemptive conflict management protocols can mediate conflict has been supported by many scholars (Pazos, 2012; Xiaojing Liu, Magjuka, \& Seung-hee Lee, 2008). Ayoko et al. (2012) conducted a study with university students who were organized into online groups and went through several stages of group development to complete a project. Ayoko et al. proposed that due to the lack of F2F communication that often results in decreased emotional awareness between members, members of online groups need to be more direct in explaining their reason for disagreement, explicit in managing the conflict, and open to feedback. Staples and Webster (2007) further determined that maintaining open lines of communication, being responsive, and managing time carefully allowed teams to manage conflict effectively. Therefore, if groups develop good communication norms early, they set themselves up to be more successful later and have less conflict.

\section{Decision Making}

In addition to conflict management styles, several studies focus on decision-making capabilities in online groups. Many organizations, in an effort to alleviate time constraints and organizational pressures, strategically utilize online groups to enhance productivity and facilitate increased creativity, with the hope that the influence of heterogeneity on decision-making will lead to positive outcomes (Gilson et al., 2015). While heterogeneity itself is an important consideration, organizations must also decide whether and how to make decisions about group formation and, in some cases, how the group will make decisions. The concept of heterogeneity is discussed more in the following section on cultural differences.

Jehn (1997) found a positive relationship between cognitive conflict and decision-making quality in F2F groups (Lira et al., 2007); however, the research and theory applying Jehn's conclusion to CMC groups are not conclusive (Stark et al., 2014, p. 225). Lira et al. (2007) showed a negative relationship between task conflict and acceptance of the group's decision; however, other studies have shown that conflict can also increase satisfaction with the group's decision. While Stark et al. (2014) did not find a positive relationship between task conflict and decision-making quality, others have. For example, O'Neill, Hancock, Zivkov, and
Larson, (2016) found that F2F groups are more effective than online groups in all decision-making behaviors, especially when the online team is told there is a correct solution. Therefore, existing research on conflict and decision-making quality have received mixed results and do not always examine the same variables (e.g., group outcomes, satisfaction, acceptance of group norms, decision quality), so it is unclear whether the relationship between conflict and decision making is positive or negative, which could in part be due to the type of conflict examined.

\section{Conflict type.}

Others have examined conflict throughout the group's lifecycle. "The higher the task and process conflict experienced early on, the higher the relationship conflict reported later;" however, this may only be under certain conditions (Martínez-Moreno, Zornoza, González-Navarro, \& Thompson, 2012, pp. 164-165). Yet, this finding further emphasizes the importance of establishing good social norms early on. They also found that in text-based synchronous online groups, early task conflict did not significantly predict subsequent relationship conflict (Martínez-Moreno et al., 2012). This finding may indicate that not only do F2F and CMC groups handle conflict differently, but also that different kinds of CMC groups (such as collocated or distributed, or different modes of CMC) may handle conflict differently. While different types of CMC groups may handle conflict differently, it is generally better to have task conflict over other forms of conflict.

\section{Group formation.}

Research has compared decision-making processes in F2F and CMC groups, determining that F2F groups make decisions about three times as fast and consider more unique information than online groups, likely because instant-messaging as a means of communication is more time consuming (O’Neill, Hancock, Zivkov, Larson, \& Law, 2016). Online groups form "in a way that makes good group decision making difficult. As a result, they are more concerned about issues other than making good decisions" (Branson et al., 2008 , p. 68). Because of this, conflict can arise when groups are more concerned about other issues (e.g., who is in the group, who the leader will be, and what the task is). Therefore, it is important to understand how and when to use certain strategies (e.g., assigning groups, random groups, and allowing individuals to create their own groups) to form 
groups to prevent unneeded group conflict.

In some cases, online task groups form naturally (e.g., a group of online students creating an online study group) and, other times, online groups may be assigned (e.g., by supervisor for a specific project). For example, online groups make suboptimal decisions when group members are more concerned about maintaining power than they are pooling their information and developing better models of the problem (Branson et al., 2008). Furthermore, anonymity in group decision making does not guarantee better decisions. Rather, performance in decision-making groups depends on the social context and relevant social norms, as well as on system characteristics, including anonymity (Postmes \& Lea, 2000). These conclusions support the idea that the type of conflict helps determine how much CMC (or virtualness) a group should use.

\section{Cultural Differences}

As a theme, cultural differences consider both organizational culture and cultural diversity. Cultural diversity has been extensively studied in F2F groups, and while diversity often has many benefits, it can also reduce group functioning or performance by increasing conflict (for a review, see Mannix \& Neale, 2005). These effects are likely to be amplified in online groups because cultural differences and miscommunication tend to increase conflict (Sessa, 1996; Shin, 2005). Much of the literature regarding the theme of cultural differences indicates that positive online group outcomes are often not realized due to conflict. Furthermore, in diverse online groups, there is an increased risk of miscommunication and misunderstandings. Due to the dispersive nature inherent in online groups, conflict often arises as a consequence of organizational culture and cultural diversity among group members despite that location variability can also be a benefit for online groups.

Intercultural group members might differ in their language, religion, holidays, time zones, norms, values, and dimensions (Paul \& Ray, 2010). These differences can lead to conflict due to lack of F2F task and social interaction, lower levels of trust, different communication styles, and lack of overall process structure, which inhibit perceptions of team performance among group members (Ferreira, Lima, \& da Costa, 2012; Montoya-Weiss et al., 2001; Yilmaz \& Peña, 2014). For example, Yilmaz and Peña (2014) discovered that online team members have positive attitudes to- ward members of similar social identity or categories, which impact members' collaboration processes. It is also worth noting that online groups may not be as aware of these differences because they can, in some cases, be concealed online.

The topic of cultural differences among members was a focus of much of the literature, and consequently, the subthemes of organizational culture and cultural diversity emerged during our analysis and are discussed in greater detail in the following sections.

\section{Organizational culture.}

Organizations often harness online groups to accomplish complex tasks by assembling a wealth of varying perspectives (Chiravuri et al., 2011). Also, task conflict arising from diverse groups can have positive impacts on group performance (Sessa, 1996, p. 102). However, the current literature reveals that the positive outcomes associated with diverse online groups are often not realized (Shin, 2005).

Scholars also argue that differing organizational process structures and contexts create conflict. Montoya-Weiss et al. (2001) determined that inconsistent temporal coordination among globally dispersed group members often contributes to conflict, and Hinds and Mortensen (2005) explained that the lack of a shared context leads to misunderstandings. Horwitz et al. (2006) revealed that workers who collaborate at a single location develop a common culture and norms, which does not often manifest among online groups in different locations. These findings suggest that the lack of a single organizational culture-which is constructed by the physical environment, ad hoc personal interactions, and coordinated processes-contributes to increased conflict among CMC groups due to resulting miscommunication. F2F teams exist in an organizational culture that shares these characteristics, so conflict related to these antecedents is less likely to occur.

\section{Cultural diversity.}

There is some inconsistency in the literature pertaining to how to mediate the effect of culture so that unproductive conflict does not manifest. Some scholars suggest bridging the cultural divide by making use of video conferencing tools to allow for nonverbal cues (Ezz, 2015). However, other scholars advise that leaner media, such as email, allow for effective communication because communicants have time to analyze and construct an appropriate response (Grosse, 
2002). Conflict in online groups is often perpetuated by delayed communication, differences in time zones (MontoyaWeiss et al., 2001), lack of F2F interaction, and language barriers (Ayoko et al., 2012). Nonverbal cues are valuable sources of information for communication that are often absent when using CMC. Yet, the lack of cues and asynchronistic nature also allow time to craft more thoughtful messages and manage identity. Further, the lack of cues also makes it difficult to interpret the communicative meaning. The resulting miscommunication is a barrier to successful online group work.

Further, Horwitz et al. (2006) emphasize that because of this increased risk of miscommunication among culturally heterogeneous groups, these groups need to meet F2F early in-group formation to establish trust. Research on heterogeneous groups also shows that the cultural diversity of an online group can negatively influence perceptions between group members, which can develop into reduced frequencies of constructive task conflict (Paul \& Ray, 2010). Additionally, organizations should require diversity and sensitivity training among management and employees (Buengeler, Klonek, Lehmann-Willenbrock, Morency, \& Poppe, 2017; Horwitz, Bravington, \& Silvis, 2006). Ezz (2015) further explores this issue, determining that managers of online groups should not only become better-educated interculturally, but should seek to cultivate trust through regular leader-member exchange of information. The current literature also suggests that the intervention of a competent leader can mitigate the conflict in culturally heterogeneous online groups (Garrison et al., 2010; Wakefield et al., 2008). However, research does not yet fully explore the relationship between leadership and conflict.

Given the salience of literature regarding the individualism-collectivism dimension of intercultural communication, Paul et al. (2004) compared virtual teams in a laboratory study involving culturally heterogeneous and homogeneous groups. Their study focused on how group diversity affected on the collaborative conflict management style. They found that group diversity had a moderating influence on performance and collaborative conflict style, and that the collaborative style was positively associated with performance (Paul et al., 2004). Further, they discovered that collectivistorientated groups were more collaborative in their conflict management style, whereas individualist-orientated groups were less collaborative. The authors further indicated that because the cultural orientations of team members may dif- fer, the process of motivating members also differs, which means that managers must carefully consider the cultural composition of a group to achieve group and organizational goals (Paul et al., 2004).

\section{Trust}

Online groups have more needs than F2F groups for trust, leadership, communication, and technology (Ezz, 2015). Researchers have argued that trust and, by extension, team cohesion are some of the greatest challenges in online groups (Garrison et al., 2010; Malhorta, Majchrzak, \& Rosen, 2007). Further, trust is crucial to online groups' performance (Garrison et al., 2010) and is essential for smooth operation and cooperation (Jarvenpaa, Knoll, \& Leidner, 1998; Msanjila \& Afsarmanesh, 2008). Since performance is a commonly studied topic in conflict and because performance is highly linked to trust, it is also important to understand how trust functions differently across group types. Trust needs to be established in online groups, which is difficult if the organizational group meets solely online and has never met in person to establish an interpersonal connection. Therefore, it is important for online groups to take steps to build trust between members. For example, getting to know one another on a personal level at the beginning of online (video) meetings could help recognize each individual as a person.

Other studies have looked at how trust develops in online groups. In online groups, trust-building exercises significantly influenced the effect of other group members' perceptions of their ability, integrity, and benevolence (Jarvenpaa, et al., 1998). Furthermore, overall group trust is most strongly predicted by group members' perceptions of other members' integrity in the early stages of the group (Jarvenpaa et al., 1998). Yu and Kuo (2012) placed conflict and the resulting trust at a later stage of group development; they found that overcoming group conflicts builds stronger bonds among group members, which provide more opportunities to interact with their group and communicate their individual needs (Yu \& Kuo, 2012).

Additionally, trust develops quickly in the beginning of work-oriented online groups, and trust affects online groups differently in different situations (Jarvenpaa, Shaw, \& Staples, 2004). Swift trust is based on group members' beliefs imported from their past experiences, and these beliefs are important in the initial development of work-oriented online groups; swift trust serves as a proxy for members to assess 
others' reliability and competence in completing their work (Kuo \& Yu, 2009). Therefore, online groups need to develop trust early on (Horwitz et al., 2006).

The relationship between online group members becomes stronger as group members learn more about one another (Kuo \& Yu, 2009). As group members are assured of each group member's individual competencies, they become more trusting of those members. Furthermore, group members use their prior experiences in groups to assess the costs and outcomes associated with maintaining a relationship with the group. They also use their past experiences to assess other group members' competencies and predict how other group members will behave (Kuo \& Yu, 2009). Therefore, having conversations about how the group will operate and the roles of each group member are important for gaining trust within the group.

Not all groups meet solely online; some groups meet partially online and partially F2F. In these mixed groups, the amount of time they spend online influences conflict and trust within the group. Bierly, Stark, and Kessler (2009) found that the more virtual the group, the more likely that the effect of relationship conflict on the group members' trust would be negative. Further, they found that as virtualness (or the amount of CMC interactions) a group has increased, relationship conflict had a more "deleterious effect" on the group because there were fewer opportunities for personal interaction among its members and fewer opportunities for them to engage in "conflict resolution activities" (Bierly et al., 2009, p. 560).

Trust and communication go hand-in-hand, even though they are two separate behavioral constructs (Sarker, Ajuja, Sarker, \& Kirkeby, 2011, p. 284). Sarker et al. (2011) conclude that trust mediates the effect of communication on performance, meaning that a communicative individual will be more likely to be trusted and will, therefore, be a higher performer in the group. Furthermore, Germain (2011) argues that decreased trust among online group members reduces knowledge sharing among them, which negatively impacts their performance. This research suggests that online groups that also meet F2F might have less conflict.

\section{Emotion management.}

Related to trust, managing emotional reactions in online and F2F groups helps manage conflict. Research suggests that conflict and emotions are intertwined, and that conflict can be both an antecedent and a consequence of emotions
(Ayoko et al., 2012; Bodtker \& Jameson, 2001; Jehn, 1997). Ayoko and Callan (2010) researched the relationship between managing emotion and conflict, and they found that task and relationship conflict engender high levels of emotional response among group members, which can potentially lead to conflict (p. 223). Ayoko et al. (2012) studied the link between conflict and the emotional behaviors of online group members, and they found that when online groups communicate their emotions (either positive or negative), team members "develop a shared understanding of the task goals and the processes needed to accomplish the goals" (Ayoko et al., 2012, p. 167). Further, when group members shared their negative emotions, groups were better able to identify gaps in the team's knowledge and better clarify their goals and how they will achieve them. This conclusion supports Keltner and Haidt (1999)'s finding that emotional expression helps individuals respond to social events, including conflict.

The literature shows that in F2F groups, revealing emotions leads to conflict (Ayoko \& Callan, 2010). However, in online groups, revealing emotions creates a shared understanding among group members (Ayoko et al., 2012). Thus, members of hybrid groups must carefully manage their emotions in a way that elicit positive outcomes of emotive disclosures. The literature would suggest that in hybrid groups, emotions should be conveyed in CMC interactions as opposed to $\mathrm{F} 2 \mathrm{~F}$ interactions so that the benefits of emotive expressions can be fully realized. The following section discusses implications and areas for future research for each theme. Table 1 provides a summary of our thematic findings.

\section{Thematic Implications and Future Research}

Our review focused primarily on task-oriented work groups, and future research may be able to extend this to other types of goal-oriented groups. Doing this will provide a better understanding about whether the same factors are present in different kinds of online groups. The current scholarship about conflict in task-oriented online groups reveals substantial differences compared to conflict in F2F groups, and we discuss the implications of these differences in the following sections.

\section{Conflict Management Implications}

Many strategies proposed by researchers are theoretical conclusions, rather than empirical findings. More evidence 
is needed to generate conclusions that allow organizations to confidently build their groups and implement communication procedures so that effective conflict can take place and unproductive conflict can be avoided or carefully managed. For example, organizations could implement online conflict management training (Martínez-Moreno et al., 2015) and provide communication technologies that allow and encourage more informal interactions (Correia, 2008; Yu \& Kuo, 2012). Moreover, organizations could enhance performance outcomes by promoting collaboration strategies (Paul et al., 2004) over withdrawal strategies (Yu \& Kuo, 2012). Additionally, the existing literature seems to only imply a relationship between conflict or conflict management and leadership styles. A closer examination linking these two concepts would benefit the understanding of how leadership styles influence group conflict. Such understandings would provide organizations with information about how their leaders can best manage different types of online groups to avoid and manage conflict.

\section{Leadership Implications}

Related to this, a good deal of literature exists on conflict management and leadership, but more research is needed that focuses on leadership in online groups. For example, some early literature has examined how the technology and media that leaders choose influence a group's performance (Sivunen \& Valo, 2006). Therefore, the leader's choice of media matters in how well it will work for a group, so leaders in charge of making these decisions should be trained to select media that will work best for the group. However, more research is needed to understand which media work best for certain group tasks. For example, it is likely the case that text-based media will not be ideal for brainstorming situations, but it could be the case that text-based media would be best for voting or decision-making situations. In the past, accessibility was one of the main factors in selecting a communication technology to use in an online group (Sivunen \& Valo, 2006). It would be important to examine this now since more communication technologies are readily available to assist with group work and have become more widely used and accessible in recent years. Because of the increased number of accessible technologies and the affordances they offer, it is likely that factors other than accessibility (e.g., editability, permanence, immediacy, and synchronicity) factor into a leader's selection of communication technology in an online group. For example, the age of the group members or the type of task being completed may be more prevalent factors. In this sense, it could be the case different generations prefer different technological features.

\section{Decision Making Implications}

Studies on decision making tend to focus on different aspects of decision making and conflict such as decision quality, conflict type, group formation and have mixed findings. Further research is needed to clarify and understand the results. The studies focusing on the same topic areas generally receive mixed results about whether the relationship between conflict and decision-making is positive or negative. Future research should aim to replicate the existing studies to understand the role conflict has on decision making. Doing so would provide organizations with a clearer idea of how decisions are best made in online groups and of the various possible mediating or moderating factors related to decision making that may influence group outcomes.

\section{Cultural Differences Implications}

In this theme, we identified three additional areas for future research.

First, it is important to understand whether specific cultural groups have different signs of conflict in online groups. Many researchers recognize the impact cultural differences can have on conflict in CMC teams (Maznevski \& Chudoba, 2000) but do not factor this variable into their studies, often controlling for cultural differences by focusing on homogeneous cultural groups. Further, studies often focus on one culture or compare practices between different cultures; more studies should observe conflict in cross-cultural teams. Mortenson and Hinds (2001) recognize the importance of comparing co-located, domestic distributed, and internationally distributed teams. Therefore, studies that replicate this method would build upon online group conflict literature. Additionally, besides the study conducted by Paul et al. (2004), few studies focus on cultural dimensions that impact communication (e.g., individualism or collectivism) as they correspond with conflict in online groups. A clear focus on communication could require scholars to initiate studies that are focused on specific cultural groups. Such findings could reveal indicative measures and strategies that organizations could employ to mitigate the influence of conflict on group 
performance and productivity.

Second, research regarding strategies for alleviating miscommunication (through rich and lean media) has had mixed findings. Ezz (2015) advised that to allow for nonverbal cues, richer media should be used to avoid miscommunication that often leads to conflict. However, Grosse (2002) recommended that because leaner media gives individuals time to formulate an appropriate response, miscommunication is less likely. Because of this, future research should aim to replicate existing studies to determine which type of medium promotes effective intercultural communication and reduces the likelihood of conflict and misunderstanding.

Additionally, pending availability of quantitative data, future meta-analyses on the topic will be able to provide a clearer understanding of the moderating variables for alleviating miscommunication. Given that cultural miscommunication is a salient issue among online groups, future scholars should focus on research that directly studies avenues of conflict mitigation, perhaps using media richness theory as a model. For example, rather than suggesting organizations should make use of lean or rich media among online groups at the end of a study to alleviate tensions associated with cultural diversity, scholars could comparatively study the effectiveness of lean and rich media, perhaps on a continuum, among work groups. This comparison could be the central focus of the study so that research draws definitive conclusions, rather than theoretical propositions.

Related, the literature cites cultural misunderstandings as a consistent source of conflict (Ferreira et al., 2012; Paul $\&$ Ray, 2010); however, the findings and recommendations are inconsistent. Therefore, a third area for future research would be on how conflict can be best managed cross-culturally and to determine the factors that influence the differences in results and recommendations across studies. Related to cultural misunderstandings, the literature points to a few inconsistent findings specifically related to media richness theory.

Finally, more research is needed pertaining to how diverse online groups develop and maintain trust (given its importance among online group success), and how these processes vary across cultures. Current research does reveal that trust is a central factor that contributes to the success of online groups, often helping to prevent or mediate the occurrence of conflict. Given the importance of trust in online group conflict, it will next be discussed as a separate theme.

\section{Trust Implications}

While the literature on trust is quite extensive, little of it focuses on conflict management in online groups. Given trust's crucial role in group performance, future research should focus on the relationship between trust and conflict. Moreover, it should replicate existing studies in additional contexts. Another possible area to be addressed includes how organizations can create high levels of trust initially and maintain it throughout the duration of the group's task. Research like this would have tremendous practical implications for organizational groups who are looking for strategies to create and maintain effective online groups. Since research focusing on how emotion management reduces or manages conflict in online groups is limited, future research could explore how and when to share emotions in online groups. For example, because online group members may not know one another, they may not feel comfortable sharing their emotions. Such a finding would increase the importance of relationship building within online groups and help practitioners and organizations develop strategies for online team-building that can increase the effectiveness of the group.

\section{Performance Outcomes}

The findings of the review mirror prior findings about the influence of conflict on group performance (Martínez-Moreno et al., 2009; Staples \& Webster, 2007) because group performance has been highlighted across each of our subthemes. In terms of conflict management styles, more collaborative approaches enhance group performance (Hinds $\&$ Bailey, 2003). For decision making, group performance depends on social context and established social norms (Postmes \& Lea, 2000). Further, negative outcomes associated with cultural differences (e.g., lack of F2F task and social interaction, lower levels of trust, different communication styles, and lack of overall process structure) weaken group members' perceptions of performance (Ferreira et al., 2012; Montoya-Weiss et al., 2001; Yilmaz \& Peña, 2014). Finally, trust is crucial to group performance because it helps relationships in online and hybrid settings (Garrison et al., 2010; Sarker et al., 2011). The persistence of performance across these themes suggests that conflict plays an important role in the overall performance of online, hybrid, and F2F groups. As such, conflict should be considered an important 
factor when considering issues related to group performance in all contexts.

\section{Disciplinary Implications and Future Directions for Communication Research}

In our review, we examined literature surrounding conflict and among online and hybrid groups, and we identified what is known and what can still be examined further about four themes: conflict management styles, decision-making, cultural differences, and trust. According to Horwitz et al. (2006), online groups are more flexible and responsive, and they can also lower costs and improve how resources are utilized, which are necessary in a continuously changing global business environment (p. 474). While online groups have many benefits and are becoming increasingly popular, they are also more prone to conflict, so it is important to understand how conflict is managed in online groups. Horwitz et al. (2006) identified five necessary factors for effective online groups: communication technology and communication quality, clearly defined roles and responsibilities, team member trust and relationships, cross-cultural understanding, and organizational commitment. Therefore, it is not surprising that many of the themes addressed in this review align with the factors identified by Horowitz et al. (2006).

Overall, the literature indicates that conflict management is different in online groups, including the increased impor- tance of establishing norms and trust early in group formation (for decision making effectiveness and optimal conflict management). Future research is needed to define more thoroughly what these differences are, why they exist, how the various factors examined as a part of group work influence conflict management in online groups, and how we can use what we know about online groups to improve the quality of online group outcomes.

In addition to our recommendations above, future research should include more disciplinary approaches to the topic, including perspectives from scholars in organizational communication and extensions to other types of goal- or task-oriented groups. Future research could also more clearly develop and apply theory to examinations of conflict in online and hybrid groups. Most research on virtual teams does not use a specific theoretical framework (Schiller \& Mandviwalla, 2007), and this trend appears to hold for research on conflict in online and hybrid groups. In addition to group-specific theories such as adaptive structuration theory (DeSanctis \& Poole, 1994), media-focused theories such as social information processing theory (Walther, 1992), hyperpersonal theory (Walther, 1996), media synchronicity theory (Dennis, Fuller, \& Valacich, 2008), and the dispute-exacerbating model of email (Friedman \& Currall, 2003) hold promise for understanding how online and hybrid groups manage conflict. For example, social information processing theory predicts that relationships develop

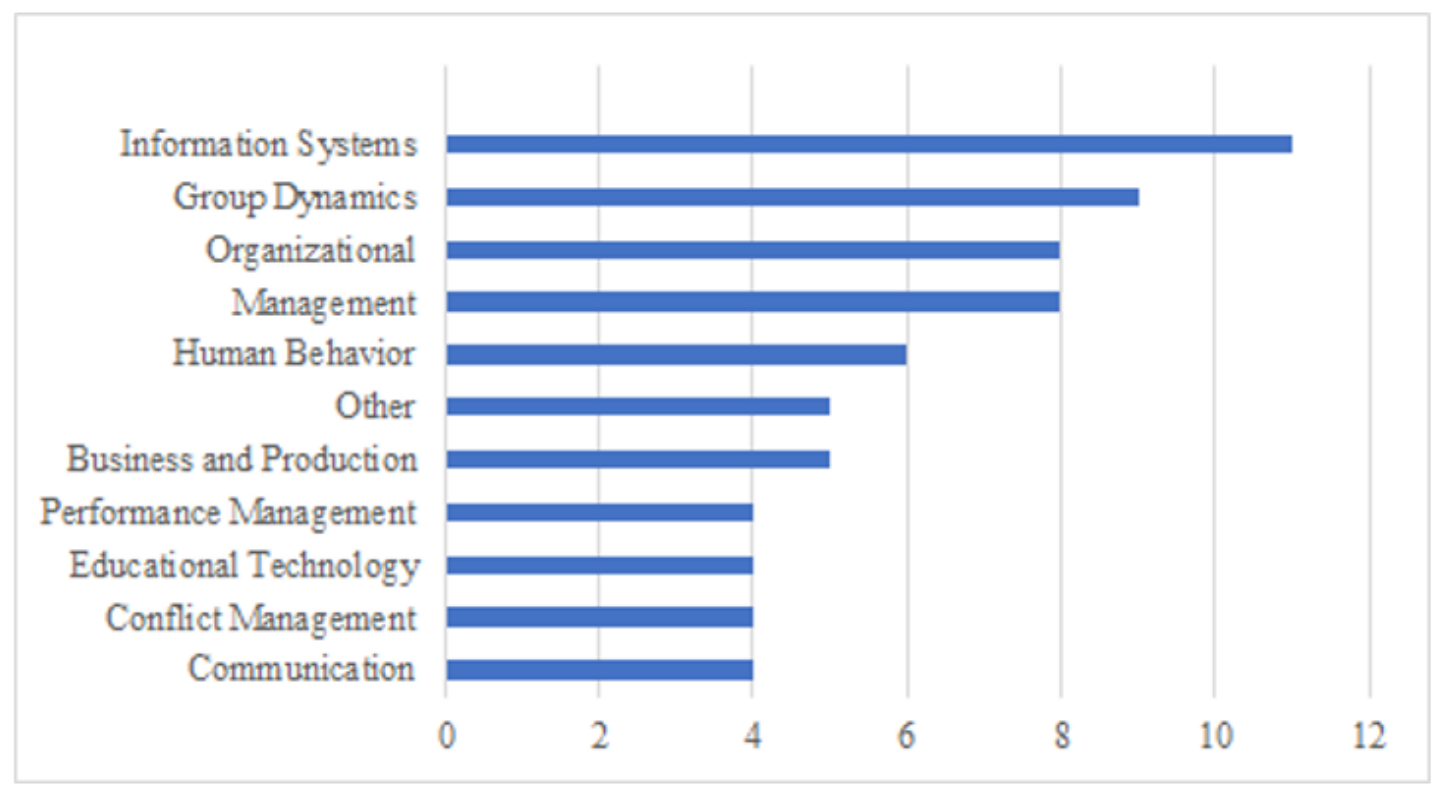

Figure 2. Number of articles by journal topic 
more slowly over CMC than F2F (Walther, 1992). Given our identification of trust and cohesion as important to managing conflict, starting hybrid groups F2F and then moving offline might "jump start" the development of trust and cohesion and improve conflict management. In contrast, research using the hyperpersonal perspective has found that impression management in mixed-modality dyads is optimized when groups meet online but quickly move offline (Ramirez \& Zhiang, 2007). Researchers could employ these theories to understand whether hybrid groups start online or $\mathrm{F} 2 \mathrm{~F}$ and when groups move from one to the other could help identify optimal conditions for effective conflict management in groups.

The most prevalent methodological strength is that the studies use real work-groups situated within organizations, as opposed to limiting themselves to a student sample. We think this is a phenomenal benefit to the discipline and to the field since these findings offer real, practical implication for the organization and important findings for the discipline. In line with our other recommendations, we think this focus on using real work-groups should, without a doubt, continue. We imagine that future research would be wellsituated to replicate this methodological approach and extend it to include workgroups from different organizations and to compare findings across different types of online groups. Perhaps as a result of using real work-groups, we found through our review that many of the studies used in this analysis lacked replication. As such, future replication studies will also help to confirm the findings of these studies, perhaps in additional contexts and in additional types of online groups.

Further, we found that research on conflict in online groups primarily exists outside of journals focused on communication and conflict management. The 68 articles included in this review came from 49 journals (or other publications) with 11 topics (see Figure 2).

We believe more interdisciplinary approaches to these topics warrant further investigation. For example, perspectives from scholars in communication, conflict management, mediated communication, psychology, and sociology may offer additional insights into conflict in online groups. Finally, literature on online groups drastically declined (see Figure 3) ssince its peak from 2008-2012. Because online groups have become the norm in organizational settings, we believe this warrants additional research on online groups, specifically as it applies to organizational communication. People are likely more comfortable with technology and CMC now than they were in 2012; however, conflict still occurs, and this remains understudied.

\section{Conclusion}

As our definitional chart illustrates, most groups are hybrid groups, therefore, it makes sense that there is overlap in

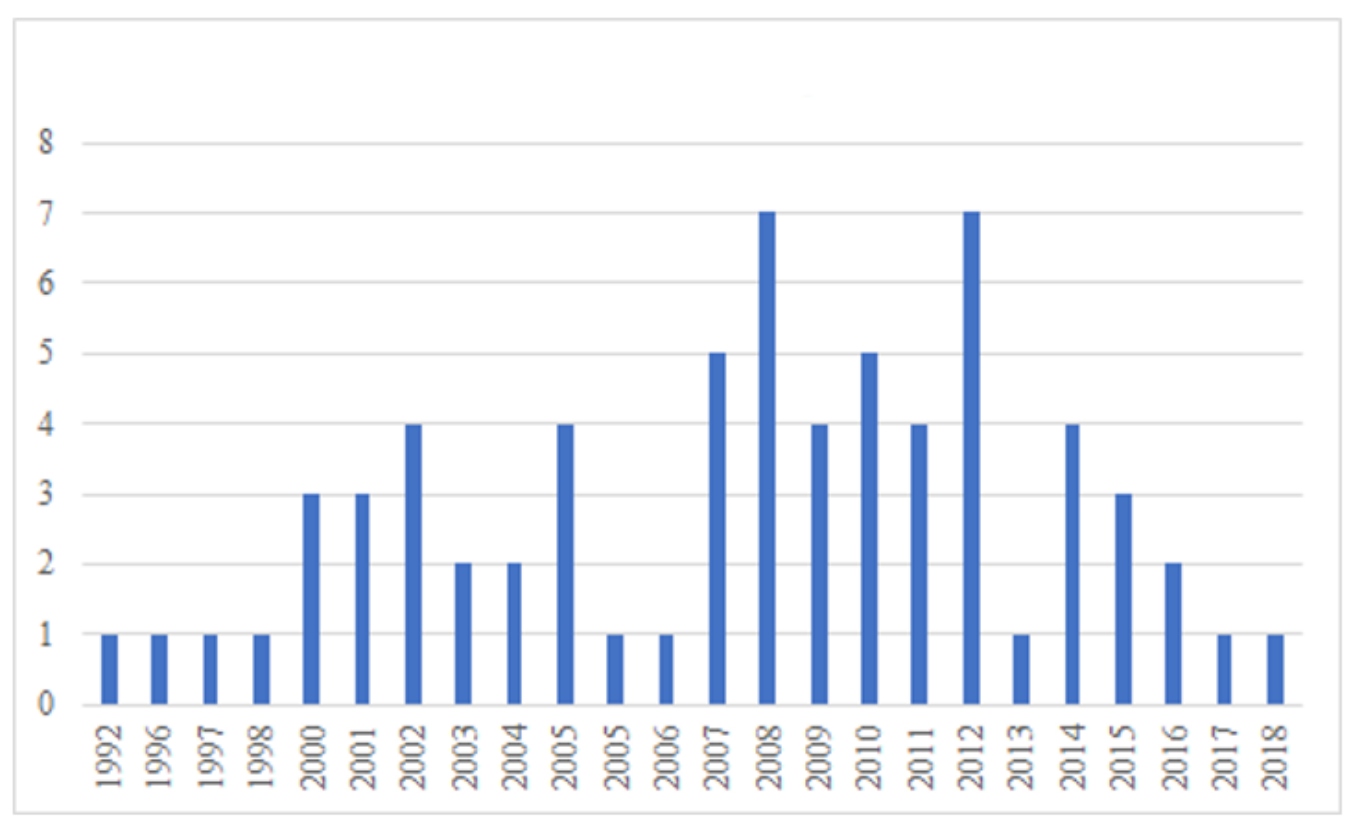

Figure 3. Articles published by year 
much of the literature on F2F, online, and hybrid groups. While the dynamics of conflict are similar in F2F, online, and hybrid groups, the literature demonstrates that the type of group determines how prevalent each dynamic is. We have also shown that conflict literature, in general, focuses heavily on group performance as an outcome variable across our four themes, which illustrates the importance of understanding how conflict works in hybrid groups. In addition to offering an extended review on the topic, other disciplines could also benefit from further exploration of the patterns and areas for future research. Organizations could also use this review to better understand the qualities of productive and effective online or hybrid groups. Further, the review provides important implications and applications for many disciplines, given the vast array of scholars who publish on the topic (including scholars in organizational, interpersonal, intercultural, group, and technology communication, as well as scholars in business administration, management, leadership, human resources, conflict management and resolution, distance education, and social psychology). Because online and hybrid work groups have become a prominent societal construct in modern organizations, it is essential that we create further understanding about conflict among these groups in communication research.

\section{References}

Ayoko, O. B., \& Callan, V. J. (2010). Teams' reactions to conflict and teams' task and social outcomes: The moderating role of transformational and emotional leadership. European Management Journal, 28, 220-235. https://doi. org/10.1016/j.emj.2009.07.001

Ayoko, O. B., Konrad, A. M., \& Boyle, M. V. (2012). Online work: Managing conflict and emotions for performance in virtual teams. European Management Journal, 30, 156-174. https://doi.org/10.1016/j.emj.2011.10.001

Baruch, Y., \& Lin, C.-P. (2012). All for one, one for all: Coopetition and virtual team performance. Technological Forecasting and Social Change, 79, 1155-1168. https://doi.org/10.1016/j.techfore.2012.01.008

Bierly, P. E., Stark, E. M., \& Kessler, E. H. (2009). The moderating effects of virtuality on the antecedents and outcome of NPD team trust. Journal of Product Innovation Management, 26, 551-565. https://doi.org/10.1111/j.1540-5885.2009.00680.x

Branson, L., Clausen, T. S., \& Sung, C.-H. (2008). Group style differences between virtual and F2F teams. American Journal of Business, 23, 65-70.

Bodtker, A. M., \& Jameson, J. K. (2001). Emotion in conflict formation and its transformation: Application to organizational conflict management. International Journal of Conflict Management, 12, 259-275.

Buengeler, C., Klonek, F., Lehmann-Willenbrock, N., Morency, L.-P., \& Poppe, R. (2017). Killer apps: Developing novel applications that enhance team coordination, communication, and effectiveness. Small Group Research, 48, 591-620. https://doi.org/10.1177/1046496417721745

Chang, W.-L., \& Lee, C.-Y. (2013). Virtual team e-leadership: The effects of leadership style and conflict management mode on the online learning performance of students in a business-planning course. British Journal of Educational Technology, 44(6), 986-999.

Chen, M.-H., \& Chang, Y.-C. (2005). The dynamics of conflict and creativity during a project's life cycle: A comparative study between service-driven and technology-driven teams in Taiwan. International Journal of Organizational Analysis, 13, 127-150.

Chiravuri, A., Nazareth, D., \& Ramamurthy, K. (2011). Cognitive conflict and consensus generation in virtual teams during knowledge capture: Comparative effectiveness of techniques. Journal of Management Information Systems, 28, 311-350. 
Correia, A.-P. (2008). Team conflict in ICT-rich environments: Roles of technologies in conflict management. British Journal of Educational Technology, 39, 18-35. https://doi.org/10.1111/j.1467-8535.2007.00731.x-i1

Cramton, C. D., \& Orvis, K. L. (2003). Overcoming barriers to information sharing in virtual teams. In C. B. Gibson \& S. G. Cohen (Eds.), Virtual teams that work: Creating conditions for virtual teams effectiveness, (pp. 214-229). San Francisco, CA: Jossey-Bass.

Dennis, A., Fuller, R., \& Valacich, J. (2008). Media, tasks, and communication processes: A theory of media synchronicity. MIS Quarterly: Management Information Systems, 32, 575-600.

DeSanctis, G., \& Poole, M. S. (1994). Capturing the complexity in advanced technology use: Adaptive structuration theory. Organization Science, 5(2), 121-147. https://doi.org/10.1287/orsc.5.2.121

de Wit, F. R. C., Greer, L. L., \& Jehn, K. A. (2012). The paradox of intragroup conflict: A meta-analysis. Journal of Applied Psychology, 97, 360-390. https://doi.org/10.1037/a0024844

Ezz, M. E. (2015). Global virtual teams: Trust and communication as facilitators and barriers to performance and team conflict resolution (Dissertation). University of Maryland University College. Retrieved from https://search.proquest.com/ docview/1711149505/abstract/6360635857F946AFPQ/1

Ferreira, P. G. S., Lima, E. P. de, \& da Costa, S. E. G. (2012). Perception of virtual team's performance: A multinational exercise. International Journal of Production Economics, 140, 416-430. https://doi.org/10.1016/j.jpe.2012.06.025

Foster, M. K., Abbey, A., Callow, M. A., Zu, X., \& Wilbon, A. D. (2015). Rethinking virtuality and its impact on teams. Small Group Research, 46(3), 267-299. https://doi.org/10.1177/1046496415573795

Friedman, R. A., \& Currall, S. C. (2003). Conflict escalation: Dispute exacerbating elements of e-mail communication. Human Relations, 56, 1325-1347. https://doi.org/10.1177/00187267035611003

Furumo, K. (2009). The impact of conflict and conflict management style on deadbeats and deserters in virtual teams. The Journal of Computer Information Systems, 49(4), 66-73.

Garrison, G., Wakefield, R., Xu, X. \& Kim, S. (2010). Globally distributed teams: The effect of diversity on trust, cohesion and individual performance. The Data Base for Advances in Information Systems, 41(3), 27-49. doi: 10.1145/1851175.1851178

Germain, M. (2011). Developing trust in virtual teams. Performance Improvement Quarterly, 24(3), 29-54. doi: 10.1002/piq.20119

Gibbs, J. L., Kim, H., \& Boyraz, M. (2017a). Virtual teams. The International Encyclopedia of Organizational Communication, 1-14, Hoboken: Wiley Blackwell.

Gibbs, J. L., Sivunen, A., \& Boyraz, M. (2017b). Investigating the impacts of team type and design on virtual team processes. Human Resource Management Review, 27(4), 590-603.

Gibson, C. B., \& Gibbs, J. L. (2006). Unpacking the concept of virtuality: The effects of geographic dispersion, electronic dependence, dynamic structure, and national diversity on team innovation. Administrative Science Quarterly, 51(3), 451-495.

Gilson, L. L., Maynard, M. T., Young, N. C. J., Vartiainen, M., \& Hakonen, M. (2015). Virtual teams research: 10 years, 10 themes, and 10 opportunities. Journal of Management, 41, 1313-1337. https://doi.org/10.1177/0149206314559946

Grosse, C. U. (2002). Managing communication within virtual intercultural teams. Business Communication Quarterly, 65(4), $22-38$.

Hinds, P. J., \& Bailey, D. E. (2003). Out of sight, out of sync: Understanding conflict in distributed teams. Organization Science, 14, 615-632.

Hinds, P. J., \& Mortensen, M. (2005). Understanding conflict in geographically distributed teams: The moderating effects of shared identity, shared context, and spontaneous communication. Organization Science, 16, 290-307. https://doi.org/10.1287/orsc.1050.0122

Hollingshead, A.B. \& Contractor, N.S. (2002). New media and organizing at the group level. In L. Lievrouw \& S. Livingstone (eds.), The Handbook of New Media. Thousand Oaks, CA: Sage, pp. 221-253.

Horwitz, F. M., Bravington, D., \& Silvis, U. (2006). The promise of virtual teams: Identifying key factors in effectiveness and failure. Journal of European Industrial Training, 30, 472-494. http://dx.doi.org.ezproxy.lib.uwm. edu/10.1108/03090590610688843 
Jarvenpaa, S. L., Knoll, K., \& Leidner, D. E. (1998). Is anybody out there? Journal of Management Information Systems, 14(4), $29-64$.

Jarvenpaa, S. L., Shaw, T. R., \& Staples, D. S. (2004). Toward contextualized theories of trust: The role of trust in global virtual teams. Information Systems Research, 15, 250-267.

Jehn, K. A. (1997). A qualitative analysis of conflict types and dimensions in organizational groups. Administrative Science Quarterly, 42, 530-557.

Katzenbach, J. R., \& Smith, D. K. (1993). The wisdom of teams: Creating the high performance organization. Boston, MA: Harvard Business School Press.

Keltner, D., \& Haidt, J. (1999). Social functions of emotions at four levels of analysis. Cognition and Emotion, 13, 505-521.

Krawczyk-Bryłka, B. (2017). Comparative study of traditional and virtual teams. TASK Quarterly, 21(3), 233-245. https://doi.org/10.17466/tq2017/21.3/o

Kuo, F., \& Yu, C. (2009). An exploratory study of trust dynamics in work-oriented virtual teams. Journal of Computer-Mediated Communication, 14, 823-854. https://doi.org/10.1111/j.1083-6101.2009.01472.x

Lee, J. Y., Panteli, N., Bülow, A. M., \& Hsu, C. (2018). Email adaptation for conflict handling: A case study of cross-border inter-organisational partnership in East Asia. Information Systems Journal, 28(2), 318-339. https://doi.org/10.1111/isj.12139

Lin, C.-P., Wang, Y.-J., Tsai, Y.-H., \& Hsu, Y.-F. (2010). Perceived job effectiveness in coopetition: A survey of virtual teams within business organizations. Computers in Human Behavior, 26, 1598-1606. https://doi.org/10.1016/j.chb.2010.06.007

Lira, E. M., Ripoll, P., Peiró, J. M., \& González, P. (2007). The roles of group potency and information and communication technologies in the relationship between task conflict and team effectiveness: A longitudinal study. Computers in Human Behavior, 23, 2888-2903. https://doi.org/10.1016/j.chb.2006.06.004

Machi, L. A., \& McEvoy, B. T. (2016). The Literature Review: Six Steps to Success (Third edition). Thousand Oaks, California: Corwin.

Malhotra, A., Majchrzak, A., \& Rosen, B. (2007). Leading virtual teams. Academy of Management Perspectives, 21, 60-70. doi: 10.5465/AMP.2007.24286164

Mannix, E., \& Neale., M. A. (2005). What differences make a difference? The promise and reality of diverse teams in organizations. Psychological Science in the Public Interest, 6, 31-55. https://doi.org/10.1111/j.1529-1006.2005.00022.x

Martínez-Moreno, E., González-Navarro, P., Zornoza, A., \& Ripoll, P. (2009). Relationship, task and process conflicts and team performance: The moderating role of communication media. International Journal of Conflict Management, 20 (3), 251-268.

Martínez-Moreno, E., Zornoza, A., González-Navarro, P., \& Thompson, L. F. (2012). Investigating face-to-face and virtual teamwork over time: When does early task conflict trigger relationship conflict? Group Dynamics: Theory, Research, and Practice, 16, 159-171. http://dx.doi.org.ezproxy.lib.uwm.edu/10.1037/a0029569

Martins, L.L., Gilson, L.L. \& Maynard, M.T. (2004). Virtual teams: What do we know and where do we go from here? Journal of Management, 30, 805-835.

Maznevski, M. L., \& Chudoba, K. M. (2000). Bridging space over time: Global virtual team dynamics and effectiveness. Organization Science, 11, 473-492.

Meluch, A. L., \& Walter, H. L. (2012). Conflict management styles and argumentativeness: Examining the differences between face-to-face and computer-mediated communication. Ohio Communication Journal, 50, 31-47.

Meyer, I. P., Bond-Barnard, T. J., Steyn, H., \& Jordaan, J. (2016). Exploring the use of computer-mediated video communication in engineering projects in South Africa. South African Journal of Industrial Engineering, 27(2), 60-71. https://doi. org/10.7166/27-2-1298

Montoya-Weiss, M. M., Massey, A. P., \& Song, M. (2001). Getting it together: Temporal coordination and conflict management in global virtual teams. Academy of Management Journal, 44, 1251-1262. https://doi.org/10.2307/3069399

Montoya, M.M., Massey, A.P., Hung, Y.C., \& Crisp, C.B. (2009). Can you hear me now? Communication in virtual product development teams. Journal of Product Innovation Management, 26, 2, 139-155. 
Mortensen, M., \& Hinds, P. J. (2001). Conflict and shared identity in geographically distributed teams. International Journal of Conflict Management, 12, 212-238.

Msanjila, S. S., \& Afsarmanesh, H. (2008). Trust analysis and assessment in virtual organization breeding environments. International Journal of Production Research, 46, 1253-1295. doi:10.1080/00207540701224350

O’Neill, T. A., Hancock, S. E., Zivkov, K., Larson, N. L., \& Law, S. J. (2016). Team decision making in virtual and face-to-face environments. Group Decision and Negotiation, 25, 995-1020. http://dx.doi.org.ezproxy.lib.uwm.edu/10.1007/s10726-015-9465-3

Ocker, R. J., \& Morand, D. (2002). Exploring the mediating effect of group development on satisfaction in virtual and mixed-mode environments. E-Service Journal, 1, 25-41. https://doi.org/10.2979/esj.2002.1.3.25

Olaniran, B. A. (2010). Group communication and conflict management in an electronic medium. International Journal of Conflict Management, 21, 44-69. https://doi.org/10.1108/10444061011016623

Paul, S., \& Ray, S. (2010). Manifested intra-group conflict in collaborative technology supported multi-cultural virtual teams: Findings from a laboratory experiment. In 2010 43rd Hawaii International Conference on System Sciences (pp. 1-11). https:// doi.org/10.1109/HICSS.2010.266

Paul, S., Samarah, I. M., Seetharaman, P., \& Mykytyn, P. P. (2004). An empirical investigation of collaborative conflict management style in group support system-based global virtual teams. Journal of Management Information Systems, 21(3), 185-222. Retrieved from JSTOR.

Pazos, P. (2012). Conflict management and effectiveness in virtual teams. Team Performance Management, 18, 401-417. http:// dx.doi.org.ezproxy.lib.uwm.edu/10.1108/13527591211281138

Postmes, T., \& Lea, M. (2000). Social processes and group decision making: anonymity in group decision support systems. Ergonomics, 43, 1252-1274. https://doi.org/10.1080/00140130050084978

Ramirez Jr, A., \& Zhang, S. (2007). When online meets offline: The effect of modality switching on relational communication. Communication Monographs, 74(3), 287-310. https://doi.org/10.1080/03637750701543493

Sarker, S., Ahuja, M., Sarker, S., \& Kirkeby, S. (2011). The role of communication and trust in global virtual teams: A social network perspective. Journal of Management Information Systems, 28, 273-309. https://doi.org/10.2753/MIS0742-1222280109

Schiller, S. Z., \& Mandviwalla, M. (2007). Virtual team research: An analysis of theory use and a framework for theory appropriation. Small Group Research, 38(1), 12-59. https://doi.org/10.1177/1046496406297035

Short, J.W.E., \& Christie, B. (1976). The Social Psychology of Telecommunications. London: Wiley.

Sessa, V. I. (1996). Using perspective taking to manage conflict and affect in teams. The Journal of Applied Behavioral Science, $32,101-115$.

Shin, Y. (2005). Conflict resolution in virtual teams. Organizational Dynamics, 34, 331-345. https://doi.org/10.1016/ j.orgdyn.2005.08.002

Staples, D. S., \& Webster, J. (2007). Exploring traditional and virtual team members' "Best Practices": A social cognitive theory perspective. Small Group Research, 38, 60-97. https://doi.org/10.1177/1046496406296961

Sivunen, A., \& Valo, M. (2006). Team leaders' technology choice in virtual teams. Ieee Transactions on Professional Communication, 49(1), 57-68. https://doi.org/10.1109/TPC.2006.870458

Stark, E., Bierly, P., \& R. Harper, S. (2014). The interactive influences of conflict, task interdependence and cooperation on perceptions of virtualness in co-located teams. Team Performance Management, 20, 221-241.

Thomas, K. W. (1992). Conflict and negotiation processes in organizations. Handbook of Industrial and Organizational Psychology, 3, 651-717. https://doi.org/10.2307/1556372

Wakefield, R., Leidner, D., \& Garrison, G. (2008). A model of conflict, leadership and performance in virtual teams. Information Systems Research, 19(4), 434-455.

Walther, J.B., \& Burgoon, J.K. (1992). Relational communication in computer-mediated interaction. Human Communication Research, 19, 50-88.

Walther, J. B. (1996). Computer-mediated communication: Impersonal, interpersonal, and hyperpersonal interaction. Communication Research, 23(1), 3-43. https://doi.org/10.1177/009365096023001001 
Workman, M. (2007). The proximal-virtual team continuum: A study of performance. Journal of the American Society for Information Science and Technology, 58(6), 794-801. https://doi.org/10.1002/asi.20545

Xiaojing Liu, Magjuka, R. J., \& Seung-hee Lee. (2008). An examination of the relationship among structure, trust, and conflict management styles in virtual teams. Performance Improvement Quarterly, 21, 77-93. https://doi.org/10.1002/ piq. 20016

Yilmaz, G., \& Peña, J. (2014). The influence of social categories and interpersonal behaviors on future intentions and attitudes to form subgroups in virtual teams. Communication Research, 41, 333-352. https://doi.org/10.1177/0093650212443696

$\mathrm{Yu}, \mathrm{C} .-\mathrm{P} .$, \& Kuo, F.-Y. (2012). Investigating the development of work-oriented groups in an e-learning environment. Journal of Educational Technology \& Society, 15(3), 164-175.

Zornoza, A., Ripoll, P., \& Peiró, J. M. (2002). Conflict management in groups that work in two different communication contexts: Face-to-face and computer-mediated communication. Small Group Research, 33, 481-508. https://doi. org/10.1177/104649602237167 
Appendix. Reviewed articles (back to text)

\begin{tabular}{|c|c|c|c|}
\hline Author(s) & Year & Publication & Theory \\
\hline Ayoko \& Callan & 2010 & Journal of Management & $\begin{array}{l}\text { Transformational and Emotional } \\
\text { Leadership Framework }\end{array}$ \\
\hline Ayoko et al. & 2012 & European Management Journal & $\begin{array}{l}\text { Affective events theory, Emotional } \\
\text { regulation theory and theories of } \\
\text { workplace conflict }\end{array}$ \\
\hline Baruch \& Lin & 2007 & Technological Forecasting and Social Change & Coopetition theory \\
\hline Bierly et al. & 2009 & Journal of Product Innovation Management & $\mathrm{N} / \mathrm{A}$ \\
\hline Bodtker \& Jameson & 2001 & International Journal of Conflict Management & $\begin{array}{l}\text { Galtung's (1996) triadic theory of } \\
\text { conflict transformation }\end{array}$ \\
\hline Branson et al. & 2012 & American Journal of Business & $\mathrm{N} / \mathrm{A}$ \\
\hline Bresnahan & 2008 & Dissertation - University of Southern California & Attachment theory \\
\hline Chang \& Lee & 2013 & British Journal of Educational Technology & Transformational Leadership \\
\hline Chen \& Chang & 2005 & $\begin{array}{l}\text { International Journal of Organizational } \\
\text { Analysis }\end{array}$ & N/A \\
\hline Chiravuri et al. & 2011 & Journal of Management Information Systems & $\mathrm{N} / \mathrm{A}$ \\
\hline Correia & 2008 & British Journal of Educational Technology & $\mathrm{N} / \mathrm{A}$ \\
\hline Cramton \& Orvis & 2003 & $\begin{array}{l}\text { Virtual teams that work: Creating conditions } \\
\text { for virtual teams effectiveness }\end{array}$ & $\begin{array}{l}\text { Social Network Theory, Social } \\
\text { Impact Theory }\end{array}$ \\
\hline Ezz & 2015 & $\begin{array}{l}\text { Dissertation - University of Maryland } \\
\text { University College }\end{array}$ & Media richness, Swift trust theory \\
\hline Ferreira et al. & 2012 & International Journal of Production Economics & $\mathrm{N} / \mathrm{A}$ \\
\hline Furumo & 2009 & The Journal of Computer Information Systems & $\mathrm{N} / \mathrm{A}$ \\
\hline Garrison et al. & 2010 & Database for Advances in Information Systems & Self-categorization theory \\
\hline Germain & 2011 & Performance Improvement Quarterly & N/A \\
\hline Gilson et al. & 2015 & Journal of Management & $\mathrm{N} / \mathrm{A}$ \\
\hline
\end{tabular}


Grosse

Hinds \& Bailey

Hinds \& Mortensen

Hollingshead \& Contractor

Horwitz et al.

Jarvenpaa et al.

Jarvenpaa et al.

Jehn

Jehn et al.

Lee, Panteli, Bülow, \& Hsu

Lin et al.

Lira et al.

Malhorta et al.

Martinez-Moreno et al

Martínez-Moreno et al.

200

2007

2007

2012

Group Practice

Martínez-Moreno et al.

Maznevski \& Chudoba

Meluch \& Walter

Meyer et al.

200
2002 Business Communication Quarterly

2003 Organization Science

2005 Organization Science

2002 The Handbook of New Media

2006 Journal of European Industrial Training

1998 Journal of Management Information Systems

1997 Administrative Science Quarterly

2008 Group Decision and Negotiation

2018 Information Systems Journal

2010 Computers in Human Behavior

Computers in Human Behavior

Academy of Management Perspectives

International Journal of Conflict Management

Social Information Processing,

Adaptive Structuration Theory

N/A

Adaptive Structuration Theory

2000 Organization Science

2012 Ohio Communication Journal

$\mathrm{N} / \mathrm{A}$

2016 South African Journal of Industrial N/A

Engineering 
Montoya-Weiss et al.

Mortensen \& Hinds

Msanjila \& Afsarmanesh

O'Neill et al.

Ocker \& Morand

Olaniran

Pangil \& Can

Paul \& Ray

Paul et al.

Pazos

Postmes \& Lea

Sarker et al.

Serce et al.

Sessa

Shin

Sivunen \& Valo

Staples \& Webster

Stark et al.
2001 Academy of Management Journal

2001 International Journal of Conflict Management N/A

2008 International Journal of Production Research N/A

2016 Group Decision and Negotiation

Media synchronicity theory

2002 e-Service Journal

Rogers' Interactive Model of Communication Process

2010 International Journal of Conflict Management N/A

2014 Journal of Knowledge Management N/A

20102010 43rd Hawaii International Conference N/A on System Sciences

2004 Journal of Management Information Systems Hofstede's cultural dimensions

2012 Team Performance Management; Bradford N/A

2000 Ergonomics

N/A

2011 Journal of Management Information Systems Social network approach

2011 Computers in Human Behavior

N/A

1996 The Journal of Applied Behavioral Science; Conflict theory (Sessa, 1994) Arlington

2005 Organizational Dynamics

N/A

2006 IEEE Transactions on Professional

N/A

Communication

2007 Small Group Research

Social cognitive theory

2014 Team Performance Management; Bradford

Rational theories of media choice and media fit theory

N/A 
Thomas

Tjosvold et al.

Wakefield et al.

Walther

Workman

Xiaojing et al.

Yilmaz \& Peña

Yong et al.

Yu \& Kuo

Zellmer-Bruhn et al.

Zornoza et al.
1992 Handbook of Industrial and Organizational N/A Psychology

2005 Human Relations; Thousand Oaks

N/A

2008 Information Systems Research

Theory of behavioral complexity in leadership

2009 Journal of Applied Communication Research Hyperpersonal

2007 Journal of the American Society for Informa- Social Identity Theory tion Science and Technology

2008 Performance Improvement Quarterly

N/A

2014 Communication Research

Social information processing theory

2014 Small Group Research

N/A

2012 Journal of Educational Technology \& Society N/A

2008 Organizational Behavior and Human Decision Processes

Information-processing/decisionmaking framework

2002 Small Group Research
$\mathrm{N} / \mathrm{A}$ 


\section{Copyrights and Repositories}

\section{() (1)}

This work is licensed under the Creative Commons Attribution-NonCommercial-3.0 Unported License.

This license allows you to download this work and share it with others as long as you credit the author and the journal. You cannot use it commercially without the written permission of the author and the journal (Review of Communication Research).

\section{Attribution}

You must attribute the work to the author and mention the journal with a full citation, whenever a fragment or the full text of this paper is being copied, distributed or made accessible publicly by any means.

\section{Commercial use}

The licensor permits others to copy, distribute, display, and perform the work for non-commercial purposes only, unless you get the written permission of the author and the journal.

The above rules are crucial and bound to the general license agreement that you can read at: http://creativecommons.org/licenses/by-nc/3.0/

\section{Corresponding author}

Jessica Kahlow

University of Wisconsin-Milwaukee (USA)

Email: jkahlow@uwm.edu

\section{Attached is a list of permanent repositories where you can find the articles published by RCR:}

Academia.edu@ @ http://independent.academia.edu/ReviewofCommunicationResearch

Internet Archive @ http://archive.org (collection "community texts")

Social Science Open Access Repository, SSOAR @ http://www.ssoar.info/en/home.htm1 